\title{
Exploration of English Vocabulary Teaching based on Cognitive Linguistics
}

\author{
Huihui Zhou \\ Dalian Art College, Dalian, Liaoning, 116600
}

Keywords: English Vocabulary Teaching, Cognitive Linguistics, Application Method

\begin{abstract}
Vocabulary is an important part of English learning. For English learning, cognitive linguistics has an important guiding role. Through the reasonable use of cognitive language, the quality of English vocabulary teaching can be effectively improved. Therefore, the correct application of cognitive linguistics to the guiding role of English vocabulary teaching can effectively improve the teaching efficiency of English vocabulary teaching. This paper briefly analyzes the guidance of cognitive linguistics on English vocabulary teaching, the role of cognitive linguistics in English vocabulary teaching and the specific application of cognitive linguistics in English vocabulary teaching.
\end{abstract}

\section{Introduction}

Cognitive linguistics is a branch of cognitive science and linguistics. By studying cognitive grammar, Mark Johnson and George Kerk created cognitive linguistics by studying the relationship between human cognition and metaphors that exist in language. Teaching has a guiding role. Cognitive linguistics differs from formal linguistics in that it emphasizes the cognitive abilities of students in the learning process. In the development of linguistics, cognitive linguistics has innovative significance. It takes semantics as the central point and provides theoretical basis for English vocabulary teaching by studying prototype theory, iconicity theory, conceptual metaphor theory and concept integration theory. The ability and level of students to apply English.

\section{Cognitive Linguistics and English Vocabulary Teaching Contents}

In the traditional English vocabulary teaching, most teachers only pay attention to instilling a large number of vocabulary into the students, filling the students' vocabulary, but neglecting the students' ability to remember the vocabulary memory. Expanding students' vocabulary is an important and fundamental issue in English vocabulary teaching. In different usage environments, the requirements for student vocabulary are not the same. For example, postgraduate exams, national four or six exams, and vocabulary used in daily life, the choice of different vocabulary is an urgent problem that students need to solve in the application process. Choosing English vocabulary according to the actual needs of students is difficult to achieve in current English vocabulary teaching. Therefore, there are still many problems in English vocabulary teaching in our country. The English vocabulary teaching in our country is too modeled and dogmatic, but it simply uses the research results of foreign use, but does not pay attention to the specific situation of English practice. The teaching of English vocabulary in our country is too theoretical, and it is difficult to combine it with real theoretical practice. In addition, because China does not pay much attention to the memory vocabulary of students, most of the students in our country have poor English vocabulary. In the face of more in-depth English vocabulary and knowledge, it is easy to be helpless and cannot make a reasonable solution. Therefore, changing the current situation of English teaching in China has an important significance for English vocabulary teaching.

Cognitive linguistics is an extension of structural linguistics and transformational grammar, and it is a supplement and a challenge to its theoretical research. The foundation of cognitive linguistics comes from the language itself, which transforms cognitive linguistics into a linguistic mechanism through the transformation of the human brain. Language cognition is manifested in the process of studying the language itself. The specific content of cognitive linguistics is to first memorize the 
language, then pay attention to the language, input its processing in the brain, and finally process the language output. Through this language mechanism, people's ability to remember words can be significantly enhanced, thereby improving the effectiveness of language teaching.

\section{The relationship between cognitive linguistics and English vocabulary teaching}

Cognitive linguistics plays an important role in English vocabulary teaching, and there are many successful cases in the teaching process. In the process of English vocabulary teaching, theoretical knowledge should be combined with the practical content of teaching, so that cognitive linguistics can provide a true and effective guidance for English vocabulary teaching. Cognitive linguistics has its unique advantages over other linguistics. Cognitive linguistics focuses on judging a person's cognitive ability through cognitive ability and ability to use language. In the process of teaching real English vocabulary, teachers should use this feature reasonably to cultivate students' cognitive ability and language use ability, thus achieving language teaching. Teaching should learn to use the method of enumerating proofs to express the basic content of linguistics to students. The main feature of integrating cognitive linguistics into English vocabulary teaching is to improve students' ability to understand the definition of lexical prototypes, so as to fundamentally master English and make them have a deeper understanding of English vocabulary.

\section{Cognitive Linguistics Guides English Vocabulary Teaching}

The basic vocabulary is the most frequently used vocabulary used by human beings in daily life. It has a basic definition and is difficult to verify by analysis. As a stable vocabulary with fixed meaning, the basic vocabulary is generally simpler and has fewer syllables. The combination of basic vocabulary is very adaptable, can appear in any context of daily communication, and has a strong ability to form words. By recognizing the basic categories of human beings, human beings gradually expand to the outside world and form a unified understanding of external things. Just like human cognition, the learning cognition of vocabulary language begins with the basic vocabulary and then gradually extends outward. In the teaching process, teaching should be based on the basic characteristics of vocabulary language learning, focusing on the basic vocabulary used in the language, and basic education for students. In the process of English teaching, with the continuous deepening of teaching, students connect a large number of basic vocabulary that they have mastered to form a huge vocabulary network. Through the core radiation of basic vocabulary, they constantly improve their vocabulary network to complete their English. Vocabulary learning. Through this shallow and deep teaching method, students can make inductive analysis of newly learned knowledge and strengthen their vocabulary memory ability. At the same time, through this kind of learning, students can combine the new knowledge they have just learned with the already mastered knowledge, and improve their ability to accept and master new knowledge through necessary review and reflection. Therefore, improving the learning of basic vocabulary can effectively improve students' ability to master and apply English vocabulary.

In the interpretation of a vocabulary, the meanings of the various meanings are not the same. Each vocabulary has a core meaning. This core meaning is called the prototype of this vocabulary. In general, other meanings are extended from the lexical prototype. Compared with the prototype meaning, other meanings have more abstract symbolic meanings. For example, the English word "head", the prototype of the head is the head of a person or an animal. Through this prototype interpretation, the meaning of the top, wisdom, leader, etc. can be extended. Obviously, these interpretations are abstract expressions of prototypes. Although they have different meanings, they all have certain internal connections. Because the interpretation of English vocabulary itself is not very different, it is very confusing when used. Therefore, in view of this special phenomenon of English vocabulary, teachers should focus on the definition of vocabulary in the process of teaching. In the extension of prototype interpretation, combined with special context, explain the intrinsic meaning of other interpretations, distinguish between prototype interpretation and The essential difference between other meanings. In the teaching of English vocabulary, part of the teaching often 
inculcates the prototype of the vocabulary with other interpretations, making it difficult for students to understand the key meaning of the vocabulary, which is prone to bias when used. Therefore, teachers attach importance to students' understanding of the meaning of vocabulary prototypes, which can effectively improve students' ability to master vocabulary and improve their English learning.

\section{The role and application of cognitive linguistics in English vocabulary teaching}

The application of cognitive linguistics in English vocabulary teaching can broaden students' imagination of words and summarize other deep meanings through the original meaning of words. For example, in the study of basic words, the teacher uses the development mode of the sacred ball to classify the vocabulary. After explaining the basic meaning of the word, the student is allowed to read the article, and the context is used to infer the meaning of the learned word in the article. By summarizing the different meanings of words in the article, we summarize the extended meaning of the word meaning. This teaching method not only saves the time of vocabulary memory, but also makes the words have the categorization nature and enhances the profoundness of students' memory.

The relationship between English vocabulary teaching and cognitive linguistics complements each other. By applying cognitive linguistics, it provides a shortcut for English vocabulary memory, which has the characteristics of tree-like memory. Teachers use the method of connection and imagination to improve the enthusiasm and initiative of students' learning, so as to carry out practical learning on the theoretical basis, improve consensus and cognition in vocabulary learning, and cultivate students' thinking ability.

English vocabulary has a special meaning in a specific context. Through cognitive linguistics, students can understand the central meaning of vocabulary and cultivate students' logical reasoning ability in extending their meanings, so that students can integrate different knowledge points and use them flexibly. English vocabulary, reducing the pressure on students to learn.

In the current English vocabulary learning, most of the vocabulary in the textbook belongs to the basic vocabulary. In the process of teaching English vocabulary, teachers should pay attention to the basic vocabulary of many vocabulary, so that they can be treated differently from other vocabulary. It is not possible to blindly increase the vocabulary burden of students in order to improve the vocabulary of students. According to the teaching progress and the actual situation of the students, teachers should give priority to helping students master the basic vocabulary in the vocabulary, thus improving students' English vocabulary learning ability. In the process of learning the basic vocabulary, teachers need to guide students to pay attention to the metaphorical meaning behind the basic vocabulary and explain it briefly. The metaphorical interpretation of English vocabulary is roughly divided into two meanings that are automatically generated in life and widely accepted by people. Strengthening students' mastery of metaphorical interpretation can effectively help students master the basic interpretation and metaphorical interpretation within the vocabulary, and understand the connection and difference between the two. The basic vocabulary occupies an important position in English vocabulary, and the metaphorical interpretation of basic vocabulary is relatively complicated. The metaphorical interpretation generated by frequent use in life requires students to master the reality of life in isolation. Teachers should focus on guiding students to master this ability in the teaching process, improve students' self-learning ability, and train students to communicate according to the definition of basic vocabulary. Inductive, so as to grasp the extended interpretation of the vocabulary. Therefore, students' understanding of the metaphorical interpretation of basic vocabulary can obviously help students to expand the definition of basic vocabulary, thereby expanding students' English vocabulary and improving the efficiency and quality of students' learning English vocabulary. It is of great significance for students to master English vocabulary knowledge. 


\section{Conclusion}

Through a comprehensive overview of cognitive linguistics and English vocabulary teaching, this paper introduces the iconicity theory, prototype category theory and conceptual metaphor theory in linguistics, and comprehensively explores the enlightenment of cognitive linguistics on English vocabulary teaching. The theoretical guidance simplifies the English vocabulary teaching method, making it creative and logical in the teaching process, thereby improving students' ability to apply vocabulary, cultivating students' ability to think and self-summary, and improve the level of students' memory vocabulary in a limited time. Improve the internal comprehensive quality of students and promote the development and progress of English teaching in China.

\section{References}

[1] Wang Minsi, Tang Zhongshun. The Enlightenment of Cognitive Linguistics Theory on English Vocabulary Teaching in Primary Schools[J].Contemporary Education Theory and Practice, 2010, 2(3):88-90

[2] Yuan Na. The Enlightenment from Cognitive Linguistics to English Vocabulary Teaching [J]. Learning Weekly, 2010, (8):100-101

[3] Yang Yusong. The Enlightenment of Cognitive Category Theory on English Vocabulary Teaching [J].Air English Classroom (New Teacher Teaching), 2011, (6): 232

[4] Wang Chengwei. The Enlightenment of Prototype Theory on English Vocabulary Teaching [J]. Heilongjiang Science and Technology Information, 2011, (19): 171

[5] Feng Yan. The Enlightenment of Conceptual Metaphor Theory on College English Vocabulary Teaching [J]. Technology, 2011, (10):119,167 